\title{
A Short History of a Controversial Diagnosis
}

\author{
Alexandro Fortunato, ${ }^{*}$ Guido Giovanardi, ** Valeria D’Angelo***
}

ABSTRACT. - This work retraces the history of gender identity, a construct which came to light at the end of the sixties, and whose path we will follow up until the present day. In detail, the work focuses on the situations in which a person - belonging to what is commonly known as the trans* world - lives with a lack of correspondence between assigned birth gender and actual gender experience. We will revisit the different diagnoses connected to gender variance - in childhood, adolescence and adulthood - that have been put forward, and examine the different diagnostic classifications that have been used up to now, in order to reach the discussion of this theme in a psychoanalytic field. We will highlight how, alongside pathologizing theories, the psychiatric and psychoanalytic fields have become enriched via theoretical and clinical knowledge that enhance and recognize the depth of the subjective experience of trans* people, without stopping therefore, at a simply reductive diagnosis.

Keywords: Gender identity; diagnosis; trans*; sex; gender; psychoanalysis.

\section{Introduction}

The history of transgender ${ }^{1}$ people is much older and more complex than that of its diagnosis. We can in fact find traces of it in many cultures and societies of the past with alternate vicissitudes. However, it is only in the

*Psychologist, a psychotherapist, PhD, member of SIPsIA. He works at the Research Unit on the development of Gender Identity, Department of Psychodynamic and Clinical Psychology, "Sapienza” University of Rome. E-mail: fortunatoalexandro@gmail.com

**Psychologist, a psychotherapist in training AIPA, PhD. He works at the Research Unit on the development of Gender Identity, Department of Psychodynamic and Clinical Psychology, "Sapienza" University of Rome. Visiting scholar at the Gender Identity Development Service (GIDS) at the Tavistock Clinic in London.

***Psychologist, a psychotherapist and a member of SIPsIA.

${ }^{1}$ In this article, we will use the adjective "transgender", sometimes abbreviated to "trans*", as the umbrella term to indicate an identity and condition that is attributable to gender variance. As a noun, we preferred the term "transsexualism", because it is the most used by psychoanalytic authors. 
last century, with the development of psychiatry, that western culture has decided to deal with this topic and examine not only the pathology and suffering, but also the underlying life experience. We can begin our story of diagnosis with the invention of the word transsexual, which Hirschfeld $(1910 ; 1923)$ began using to distinguish between transvestism and transsexualism as phenomena that were different from homosexuality. The term "transsexual" was then picked up and transformed by Cauldwell (1949) with the definition of psychopathia transexualis, a wording that recalled the title of Richard von Krafft-Ebing's book, Psychopathia sexualis, (1886) to indicate a clinical picture characterized by distress related to the refusal of one's anatomical sex. The work by Money (1955) led to the theory that sex and gender were not necessarily interconnected and to the definition of the role of gender, by differentiating a series of feelings, beliefs and behaviours that define being male or female from biological characteristics. According to Money (1994) gender dysphoria is a construct connected to multiple and complex physiological and psychological causes. Nevertheless, the media event that allowed for transsexuality to be broadcast to the masses and to the medical-psychiatric community was the case of George/Christine Jorgensen (Hamburger Sturup, \& Dahl-Iversen, 1953), which was considered the first successful case of gender reassignment. However, Christine Jorgensen was not the first in history: in 1933, the Danish painter Einar Wegener became Lili Elbe. This story was told in the book Man into Woman (Hoyer, 1933), and then later in the book by David Ebershoff The Danish Girl (2000), from which a film of the same name was also made (Tom Hooper, 2015). The outcome of the procedure was fatal and, for this reason the story of Lili Elbe is less notorious than that of Jorgensen. From the transformation of George/Christine onwards, medical technology has made huge leaps and bounds: currently trans* people have hormone therapy and surgical procedures available to modify their anatomy in a safe and functional way.

The progress of scientific medicine and the social changes that followed these events have profoundly modified the concept of the relationship between sex and gender, both in scientific settings and in the general population.

In spite of this, up until a few decades ago the most popular opinion towards transsexualitsm was that of an illness similar to a psychotic delirium.

Nowadays psychiatry, together with the legislations of different, sees an incongruence between gender experience and biological sex as a "normal variation of human gender expression" (Drescher \& Byne, 2013). The last ten years or so have been crucial as they have been characterized by a campaign aimed at de-pathologizing the trans* identity; this began during the preparation phase of the latest version of the DSM. With the publication of the DSM-5 (APA, 2013) a first step was made towards a small revolution 
that ended in 2019 with the publication of the ICD-11 (WHO, 2018). Indeed, since the publication of the DSM-5 and its creation of the category Gender Dysphoria (GD), being trans* is no longer considered as pathological, unless there is a certain suffering tied to the condition. The ICD-11 has eliminated the dysphoria from its section on mental health problems and has instead placed gender incongruence in a separate section from that of psychiatric pathologies. We will shortly go into more detail regarding the diagnostic side of the trans* condition within psychiatric manuals.

Analyses carried out by many international research groups, including Italian ones, have been crucial in exploring the trans* identity from many different points of view (Amodeo, Picariello, Valerio, \& Scandurra, 2018; Fisher et al., 2013; Giovanardi et al., 2018; Giovanardi, Morales, et al., 2019; Lingiardi, Giovanardi, Fortunato, Nassisi, \& Speranza, 2017; Ristori et al., 2020; Scandurra et al., 2018; Vitelli et al., 2017).

This journey is comparable to that of homosexuality, that until 1973 was classified as a mental disorder, it then became an ego-dystonic concept in 1980 , to then disappear from official psychiatric radar. The downgrading of homosexuality from mental disorders was a fundamental step for its depathologization, and something similar seems to be happening with transsexuality.

\section{The construction of gender identity}

The construction of identity is a complex process in human development. From birth, every child carries a series of innate characteristics that fuse together with the environmental characteristics that surround him or her. Already at about three years of age children recognize the existence of the male and female categories and can define themselves as belonging to one or the other. Generically we refer to this recognition of belonging to a certain category with the term gender identity. As we grow, we become aware that gender remains stable and does not change depending on clothing, behaviour or time. Together with this gender stability, there are also stereotypes tied to it, which often come from the culture in which we live. Therefore, gender is influenced by a biological pathway and a cultural one: how much these two factors weigh, and which is predominant, is the source of much debate. To enrich this journey even further, sexuality develops, and with it, sexual orientation.

These three aspects: sex, gender and sexuality, are intertwined and influence each other in a complicated knot made of personal and social factors, which will form a very important part of the identity of a person. It is a subjective, unpredictable and multifactorial process. At around three or four years of age gender constancy is consolidated, and it is in this period of time 
that a variation may take place that can last throughout development, or not. In time, this variation has taken on many names and has been hotly debated, especially because in children it can develop into many different hues.

There are in fact many situations where transgender identity is not that strong and can be broadly described as gender variance.

Speaking of developmental age, we must emphasize that children with gender variance can be very different from each other. Some children use the signs identified as dysphoric as symptoms of other conditions, or as signs of other mental suffering. Hence, not all children that demonstrate so called cross-gender behaviours can be truly considered dysphoric. In other children, these signs remain stable in time, leading to a development of gender incongruency. At the moment, it is unclear which factors lead to either of these situations: we do not know how to distinguish persisters, which are those children that continue to present dysphoria even in later stages of development, from desisters, those that no longer manifest it as they grow.

When it comes to adolescents there are some differences: they can in fact find themselves in a situation that is more similar to a child or an adult, depending on their level of development. The difference lies in the fact that while in children the phenomenon can be transitory and have many nuances, in adults the situation is more stable. Adolescents often present themselves with a level of certainty when it comes to the gender they are experiencing. Nevertheless, the arrival of puberty, sexual development and bodily changes can call everything into question and can bring about new acquisitions.

Adolescents often present a more pronounced suffering with regards to their bodies, which, at this stage, develop more secondary sexual characteristics. While a child can dream of magically becoming the gender he or she experiences, an adolescent faces the inescapability of biology. Sexual development can therefore bring about more suffering and more of a will to change one's body so that it reflects an internal image.

Even though adults can present a multitude of different situations, they are more stable in time. Adult gender variants can or cannot bring about changes to their bodies, to their lifestyles and family life, depending on their subjective experience. What must however be underlined, is that in adults the physical procedures to modify one's body, such as hormone treatment or surgery, can be considered a part of the intervention for attenuating the suffering that we consider being part of the diagnosis of Dysphoria.

\section{A history of diagnosis and diagnostic criteria}

If we retrace the history of the diagnostic transformations of transsexual conditions, one will note that in the last 10 years general conceptions have 
changed (Beek, Cohen-Kettenis, \& Kreukels, 2016). The presence of transsexualism in diagnostic classifications is obviously tied to the times. The most pathologizing conditions were present in the first editions, which would group together issues regarding gender and those connected to sexuality; they interpreted gender incongruence as a perversion. The more recent editions recognized the errors of the past and conceptualized this incongruence as one of many possibilities in human development. The journey of this diagnosis has not occurred without controversy. The debate on the need for a diagnosis began at the beginning of the 90's when the initial criticisms arose, especially regarding childhood (Drescher, 2010; Drescher et al., 2016). For example, following the inclusion in the DSM-III of the diagnosis for gender identity disorder in childhood, the queer studies scholar and feminist Eve Kosofsky Sedgwick (1993) stated that this was just a way of reinstating the homosexuality diagnosis, which had been removed from this very edition of the DSM. According to Sedgwick, the diagnosis allowed for the treatment of children who did not conform to a specific gender and to therefore try to prevent adult homosexuality. A similar point of view was held by Richard Isay (1997) according to which this diagnosis labelled these pre-homosexual children as psychologically disturbed. More recently Ehrbar, Witty, Ehrbar and Bockting (2008) raised the issue of the difficulty in distinguishing between children who suffer a real gender dysphoria from those who present a more general nonconformity to a gender (which in the majority of cases results in adult homosexuality). Even singular countries and governmental organizations, the European Parliament and other agencies and groups for LGBT rights have taken a negative stance towards gender identity diagnoses.

Many international experts, at the more important specialist centres have instead expressed their favour of maintaining this diagnosis (e.g. CohenKettenis, 2001; Zucker, 2010), stating the necessity for children, like adults, to be followed by specialized experts where multi-disciplinary teams can manage the complexities that their families may face; especially in reducing the stigma at a familial, educational and social level. Lastly, in 2013 the World Professional Association for Transgender Health (WPATH), contacted a group of experts and organized a vote for or against the removal of the diagnosis from the ICD-10; the result was split down the middle (WPATH, 2013). A similar result was obtained in a survey carried out by members of this association (De Cuypere \& Knudson, 2015; Winter, De Cuypere, Green, Kane, \& Knudson, 2016).

At the moment, the choice that the majority of the scientific community is oriented towards is that of maintaining a soft diagnosis, steered towards a description of a gender incongruence. The term incongruence is less pathologizing than dysphoria, as it does not automatically imply suffering. The reason for the decision lies in the observed need to follow a person 
through clinical observation (Drescher et al., 2016). The elimination of the diagnosis, especially in childhood, exposes trans* people to many health risks: its maintenance entails the development of specialist centres that can help families better understand the phenomenon and promote the need of a specialized training for health professionals - who are often completely in the dark when it comes to these issues (e.g. Sood, 2009; WHO, 2015).

\section{DSM (Diagnostic and Statistical Manual of mental disorders)}

The DSM (Diagnostic and Statistical Manual of mental disorders) is published by the American Psychiatric Association (APA) and presently 5 standard editions have been published as well as two revisions.

The first 2 versions of the manual did not mention gender identity at all. There was still not sufficient knowledge on the topic and there tended to be much confusion between gender and sexuality. In fact, the DSM-1 (APA, 1952) and the DSM-II (APA, 1968) put people with gender issues within the category of Sexual Deviances, in which one could find homosexuality and transvestism.

In the DSM-III (APA, 1980) the category "Psychosexual Disorders" was introduced with 4 sub-sections: Gender Identity Disorders (GID), Paraphilias, Psychosexual dysfunctions and Other Psychosexual disorders (which included Ego-dystonic homosexuality). In detail, the GID category included 3 subgroups: Gender Identity disorder in childhood, Transsexuality, and Other Psychosexual disorders. Therefore, the DSM-III introduced the diagnosis of Transsexualism for the first time, for individuals that showed a persistent desire to alter their sex and their gender role in society. The fundamental criteria for GID in childhood were: a strong and persistent desire for a child to be of the opposite sex or an insistence of being of the opposite sex; for girls, a strong refusal of their female structural anatomy; for boys, a strong refusal of their male structural anatomy or an interest in stereotypically female activities. Another difference between boys and girls was the fact that in one of the criterions for girls there was a strong denial of having a female body, while in boys the criterion was concentrated on the dissatisfaction of having a male body. These male and female differences were maintained up until the DSMIV-TR edition (Zucker, 2010).

In the revised version of the third edition (DSM-III-R; APA, 1987) the category of Psychosexual Disorders was removed and a new category was officially added: Gender Identity Disorders (GID). The GIDs were placed in "disorders usually first evident in infancy, childhood or adolescence", and they included: GID in Children, GID in Adolescent and Adult, Nontranssexual type and Transsexualism; furthermore, the Not Otherwise Specified GID described changes in gender identity that could not be clas- 
sified as gender identity disorders. The Not Otherwise Specified GID diagnosis was inserted to include people who did not have an intention of having gender reassignment surgery but who still had a nonconforming gender identity (Bradley et al., 1991; Levine, 1989). A certain confusion still persisted between issues tied to sexuality, such as sexual disorders, sexual orientation (which was still considered a pathology if not heterosexual) and gender issues.

With the DSM-IV (APA, 1994) and its subsequent revision (DSM-IV-TR; APA, 2000) there was a complete overhaul of the term transsexualism and the inclusion of GID within the section titled "Sexual and Gender Identity disorders". Therefore, in these last 2 editions, GID was again categorized together with sexual disorders. The diagnostic assessment was simplified and included one general disorder with three subtypes: GID in Children, GID in Adolescents and Adults, and GID NOS (Not Otherwise Specified). The diagnosis of Non-transsexual GID was removed for two main reasons: on the one hand the difference between this diagnosis and that of Transsexualism was not very clear, on the other hand, there was a need to separate this clinical diagnosis from the criteria in order to approve gender reassignment surgeries (Bradley et al., 1991; Bradley \& Zucker, 1997). The subcommittee that was appointed to revise the diagnosis stated that they wanted to reduce the differences between males and females, which had been criticized by various authors (e.g. Zucker \& Spitzer, 2005), and for this reason, the criterion that concerned the desire to be of the opposite sex became the same for both genders. Another novelty was that this criterion was no longer necessary for a diagnosis in the DSM-IV, based on the fact that - as clinical cases were demonstrating - in the majority of children with a nonconforming gender identity, this desire is only rarely expressed (Bradley et al., 1991). Generally, if the third edition put identity at centre stage, the fourth edition focused more on behaviours (Beek et al., 2016).

The diagnostic criteria of the DSM-IV-TR (APA, 2000) for GID described a strong and persistent identification with the opposite sex, recalling a binarism of the male-female gender, but it confused sex and not gender. The APA also added a persistent discomfort towards one's own sex or a sense of unfamiliarity towards one's own sexual role. The category of GID- NOS was the source of much confusion as it could be diagnosed in situations where there was a difficulty with gender identity, gender dysphoria, transvestism, or even intersexuality.

Lastly, one of the more significant criteria was aimed at identifying the distress and suffering of this condition. The idea of including a criterion about clinically significant distress and about compromised functioning was linked to the need of reducing false positives (Spitzer \& Wakefield, 1999). Despite the presence of this criterion, the diagnosis regarding childhood GID still received criticism: according to some authors, this new diagnosis 
(compared to the previous one) presented a threshold that was too low, and for which there would have been even more false positives (Haldeman, 2000; McGann, 2007).

With the DSM-5 (APA, 2013) the issue of GID was overcome and the focus was put on the issue of dysphoria, that is, the suffering tied to one's condition. A new label was created: Gender Dysphoria (GD). Additionally, the incongruence between experienced/expressed gender and assigned gender was introduced for the first time and non-binary terminology was used (Zucker et al., 2013). In the DSM-IV gender identity and gender roles were in fact considered as dichotomous (masculine/feminine); in the DSM-5 the same concepts take on more significance and become multicategorical (Cohen-Kettenis \& Pfäfflin, 2010; Zucker et al., 2013). Thus, not only is there no longer a reference to a disorder, but it also no longer talks about "the opposite sex", but rather of "other gender or opposite gender". The term sex is replaced by gender to avoid confusion with sexual developmental disorders and on the basis of various studies (e.g. Deogracias et al., 2010; Paap et al., 2011) the main criteria were unified.

Passing to the $5^{\text {th }}$ edition was an important transformation in terms of diagnosis - but also in the ideation - of transsexual conditions. Following criticism from different fields (e.g. Bartlett, Vasey, \& Bukowski, 2000; Hill, Rozanski, Carfagnini, \& Willoughby, 2006; Meyer-Bahlburg, 2009; Vance et al., 2010), who identified highly stigmatizing taxonomy in the DSM, the principal dilemma became that of reducing discrimination, while ensuring that individuals who needed treatment, had access to it (Drescher, CohenKettenis, \& Winter, 2012; Zucker et al., 2013).

The new diagnosis should better reflect the core of the problem, i.e., the suffering that accompanies "the incongruence between experienced/ expressed gender of an individual and the assigned gender" (Narrow \& Cohen-Kettenis, 2010). In the manual, it is stated that such a diagnosis is more descriptive and more accurate compared to previous diagnoses because it concentrates on dysphoria in GD as a clinical problem and not on identity per se. Moreover, the GD diagnosis has been separated from the other paraphilias and from the sexual dysfunctions.

Another important difference is the addition of a time frame of 6 months (for children, adolescents and adults), in order to distinguish between transitory GDs from persistent ones. With regard to the childhood diagnosis, the criterions "a strong desire to be of a gender other than one's assigned gender or a strong desire to be treated as a gender other than one's assigned gender" are necessary (but not sufficient) to make a diagnosis. In this way, the criteria of the DSM-5 are more restrictive and more transparent in their aim of identifying children who are, beyond any reasonable doubt, struggling with their gender identity (Zucker, 2010). Finally, the "expressed desire" is substituted with "strong desire", in order to include children who cannot 
express their dysphoria due to unwelcoming or coercive environments (Zucker et al., 2013).

\section{ICD (International Classification of Diseases)}

The ICD (International Classification of Diseases) is a diagnostic tool maintained by the World Health Organization. Regarding gender identity, the ICD has gone through the same dilemma that dominated the theoretical discussion from the DSM-IV-TR and DSM-5, that is, the mediation between depathologizing and the need to maintain a diagnostic label that allows trans* people to be admitted into national healthcare systems.

In the ICD-9 (WHO, 1975) the term "Transsexualism" appeared for the first time and it was classified under "Sexual Deviations and Disorders" next to Transvestism. The term transsexualism remained also in the $10^{\text {th }}$ version of the ICD (WHO, 1992), just as it did up until the DSM-III-R of 1987. The category where it was included was also similar: "Sexual identity disorders". However, the ICD was different in that it established five diagnostic categories: Transsexualism, Dual-role transvestism, Gender identity disorder of childhood, Other gender identity disorders and Gender identity disorder, unspecified. Even in this manual there seemed to be an overlap between gender, sex, gender identity and sex identity.

In the latest version, ICD -11 (WHO, 2018), the category was revised and moved from the mental health chapter to the one on sexual health, therefore, it was no longer considered a mental disorder. It is named Gender Incongruence, overcoming the concept of dysphoria that is present in the DSM-5. The category states that the incongruence is between experienced gender and assigned gender at birth. It is specified that behaviour and sexual preferences are not the basis for diagnosis, thus, leaving behind any confusion between gender, sex and sexuality.

The ICD-11 has accomplished and completed a long process that responds to the need of having a diagnosis in order to access treatments, but which is not pathologizing or stigmatizing.

\section{PDM (Psychodynamic Diagnostic Manual)}

The history of the PDM (Psychodynamic Diagnostic Manual) is more recent than the aforementioned manuals and for this reason it is less affected by the confusion present in other diagnostic systems, especially when it comes to gender, sex and sexuality. In addition, as it is a psychodynamic manual, it is not limited to a classification of symptoms, but rather tries to speak of each condition's development. 
In the first version of the PDM (PDM Task Force, 2006), GID was present in all sections: adult, children (young and old) and adolescents. In the adult section, the emphasis was about feeling as though one is in the wrong body, has felt so for a long time, and there is a desire to have anatomical organs and abilities of another gender. According to the manual this situation could die down or remain stable in time, and had to be differentiated from a psychotic delirium. The PDM gives a careful description of the mood and somatic states and of the cognitive and relationship patterns. Much of the problem was focused on a depressed mood, negative sentiments, fixations on parts of the body and social problems stemming from being trans*. It must be noted how even from the first version of the manual the focus was on the person and on the possible problems that could derive from the social stigma.

The PDM-2 (Lingiardi \& McWilliams, 2017) introduced a new section called Psychological experiences that could require clinical attention on the $\mathrm{S}$ Axis, related to Subjective Experience. In this transversal section, which can be present from childhood to adulthood, we can find Gender Incongruence, which is not dissimilar from the ICD-11. This category describes subjective experiences of specific populations and refers to the fact that individuals from these can turn to health services for mental healthcare due to the difficulties associated to certain conditions. However, they are not considered to be pathologies as such and these populations often include ethnic, cultural, linguistic, religious and political minorities, also gay, lesbian and bisexual populations, and lastly people with gender incongruence. Underlying this is the concept that, just like for homosexuality, there is no need to consider non-conforming gender identity as a pathology. However, it is a condition, which for various reasons, can present issues associated with it and these populations may require clinical attention.

This innovation therefore describes individual differences that are not necessarily sources of suffering, but it recognizes the possibility that, because of social stigma or a lack of personal acceptance, the trans* condition can (and not must) require clinical attention.

With respect to adulthood and adolescence, the subjective experience of the incongruence is described as a "marked and persistent lack of alignment between an individual's experienced (subjective sense of) gender and the birth-assigned (natal) gender", which can lead to a desire to live and be accepted as a person of the experienced gender. The mood states associated to this include anxiety, depression, suicidal ideation, anger against one's physical anatomy, panic for adolescents during puberty, pleasure and satisfaction when they are permitted to freely express their gender identity. The main cognitive pattern is that of a strong worry relating to gender, that can be similar to an obsession, which usually diminishes or disappears with transition. From the point of view of somatic states, people who have not 
completed their transition are characterized by a strong discomfort regarding their psychical anatomy, for which adolescents and adults try to hide or modify by taking hormones or having surgeries (especially with regard to secondary sexual characteristics). In terms of relationships, the majority of individuals will have homosexual relations before the transition, others however, have transitions later on, after heterosexual marriages or even after the birth of their children. Lastly, the subjective experience of the therapist (countertransference) can include anxiety, worry, repulsion or voyeuristic curiosity.

Regarding childhood, the diagnosis is similar to that in adults with more emphasis placed on behaviours. A lot of importance is also given to developmental processes for which the Manual, which describes the difference between persisters and desisters, describes a lot of variability, and an impossibility of establishing (with reliable tools) in which cases the incongruence will persist or desist after puberty.

\section{History of psychoanalysis and gender identity}

Even the history of psychoanalysis, just as the psychiatric one, follows a journey that goes from pathologizing models to others that try to give a different and more contemporary view of the phenomenon.

The first author who dealt with this topic was Stoller in his famous book Sex and Gender (1968). Before him, no other psychoanalytic author had been concerned with transgender people or had included personal theories regarding the concept of gender identity. From Freud to Stoller, what we can retrace in psychoanalytic literature mostly concerned sexuality, the sexual, psychic bisexuality and the intricate intertwining of identifications. These are concepts that are fundamental to psychoanalysis but that do not help us to understand the trans* identity fully. For Stoller, gender identity is developed very early on, in a period that goes from birth to the end of the third year of life: this originates from biological-hormonal factors, from the physiological characteristics of external genitalia and from social relationships, in particular all those behaviours that parents carry out in relation to the child's gender. According to the author the origin of transsexualism resides in an excessive intimacy between mother and child which prevents the child from overcoming the protofeministic phase, also determined by an absent fatherly figure, who does not intervene and actually unconsciously encourages the feminization of the child. For Stoller, the feministic identification of the child has nothing to do however with psychotic delirium.

After Stoller, many authors tried to grapple with this phenomenon starting from clinical cases and trying to extrapolate more general theories. What these authors have in common is that they contextualize the trans* 
phenomenon as a unitary syndrome, within pathological frameworks characterized by psychotic structures and severely narcissistic personalities.

It must be said that these theories understand certain aspects, especially connected to the clinical experience of the first years, in which trans* people begin to approach the world; there is therefore a bias that was not recognized when it came to observed patients. They were described as ambiguous, disoriented, demanding, deceptive, closed within themselves, absorbed in gender fantasies and completely resistant to transference. The same Stoller, whose interpretation of trans* identity is surely less pathological than other authors', described trans* patients as irresponsible, had a tendency to lie, and were incapable of establishing stable therapeutic relationships. These observations, however, did not take into account that access to treatments were linked to the need of authorizations for procedures and that these patients did not efficaciously represent all of the transgender world, which is still very obscure. Moreover, it must be noted that in the era that patients arrived to the offices of these psychoanalysts, they were mostly biologically male and in transition. Hence, in these theories, even the etiological research was rather complicated by the very small sample that was analysed, and we could also say, by the prejudice of the psychoanalysts themselves. In this group were (compare Socarides, 1970; Limentani, 1979; Argentieri, 2009) two female authors Colette Chiland and Agnès Oppenheimer out of all of the men.

Chiland (1997) saw transsexualism as a condition close to psychosis, that originated in the psyche following a terrifying and active primal scene, where the penis is represented as being much more dangerous than the vagina. The parents therefore push the child to want to be of another gender because only in this way can they be loved; what is missing is a mirror in which to find one's own image and one's own gender. This contradictory and psychotizing message generated a narcissistic wound and an extensive removal of childhood experiences, which resulted in a structuring of a defensive and rigid identity that denied the reality of one's body. This falling back on oneself causes a disinvestment from the relationship with the object and therefore a resistance to transferential dynamics.

Even for Oppenheimer (1991) transsexualism stemmed from a narcissistic wound, a form of après coup that occured as a compensation and defense following an intense period of conflict in which the mother did not confirm the masculinity of the child, but rather used him for her own narcissism. The father, in turn, did not intervene, did not recognize his son and did not allow the child to idolize him. In this way, the only solution for the child is to turn to his mother for his needs of idolization and experience his masculinity as a castration. Transsexual identity is therefore a hidden identity, a delusional construction characterized by a withdrawal from reality and the creation of a new reality through a mechanism of permanent acting out, which has 
stems from a hate for masculinity and a denial of homosexuality. Even Oppenheimer agrees that transsexual patients are very difficult patients that in their severely narcissistic framework cannot establish a relationship with the therapist, if not in a manipulative way.

In this phase of psychoanalytic history, sex, psychic sexuality and gender were often treated in the same way, refuting the distinction introduced first by Money and then later by Stoller. This blending together of different concepts and using process identifiers as a single key to read the trans* phenomenon has resulted in a construction of partial theories, which are descriptive only for a few patients and are not generalizable.

Recently, a novel interest in the trans* experience has led to new authors examining the topic; a series of different voices who began again from observations of new patients and of the phenomenon in more modern times. In fact, after the development of feminism and gender studies, we can no longer consider the concept of gender as univocal, but rather described in complex terms by Dimen (1991) as a "field of force", by Harris (1991; 2008) as a "necessary pretense that must be assembled delicately, and is made up of many different elements", by Benjamin (1995) as a "real appearance" or by Butler (1990) as "a copy where the original is missing". Even for this group of authors, we limit ourselves to examining in depth only two: Agvi Saketopoulou e Oren Gozlan.

Saketopoulou (2014) stated that at the root of the old conceptions about gender there is a sort of "regulatory anxiety" of the psychoanalyst and a difficulty in empathizing with the patient. Until the psychoanalyst is able to contact the patient at a deeper level by abandoning prejudice and believing that the interventions that the patient asks for are not crazy, the analyst will push away the patient, denigrating his or her profound needs. Saketopoulou, however, also cautioned that there is another risk, particularly, that of colluding completely with the unconscious fantasy of the patient and indulging their removal from the sexual body. The fundamental objective of therapy should be that of allowing for the recognition of anguish towards one's body, exploring its psychological significance, accepting the reality of the body in which one is born into, and mentalizing the intolerable somatic sensations. This does not mean renouncing to hormonal treatments and surgeries, but rather facing them in a healthy way, recognizing the body which one has. According to Saketopoulou, these interventions are not an acting-out of the unconscious fantasy but are instead attempts to adapt the shape of the body to the perceived body.

Gozlan (2018) invites us to pay more attention to the perception that the trans* patient has of himself or herself and of his or her body. According to the author, psychoanalysis must aim to allow the patient to find his or her authenticity in a transitional space in which empathic acceptance can allow him or her to confront the enigmatic condition in which he or she finds 
themselves. The transitional processes are processes of re-birth and of the creation of new meanings, in which the patient can adapt the body to his or her psychic reality, to his or her authentic Ego; this is not the body that one has but rather the one that is invested in psychically. The psychoanalyst can, in a better way than most, help the patient to manage the complex network of defenses, mournings and attempts to elaborate profound perceptions. The psychoanalyst can work on partial objects that are not integrated into the unity of the self, transforming them by giving them new meaning, in a constant tension between internal and external worlds.

\section{Conclusions}

We have tried to retrace the development and the history of the trans* experience, both from a psychiatric and psychoanalytic point of view. We observed that these two paths, that often seem parallel to each other when examining this topic, actually touch and overlap, lingering on errors in history regarding diagnosis. Scientific and cultural thinking, from the initial pathologizing of the experiences and the body, has followed a long trajectory towards liberation. Today, we can say that both in psychiatry and psychoanalysis we have reached a recognition of the profound and subjective experience and an assertion of one's own identity.

Despite this evolution in current psychoanalytic thinking, there are still instances of pathologizing tout-court, that give rise to vivacious and interesting debates (see Giovanardi, Fiorini Bincoletto, \& Fortunato, 2019).

We believe that today, following depathologization of the trans* condition, psychoanalysis has a great opportunity, i.e., of putting itself forward as a truly knowledgeable instrument for the psychic, somatic, and social experiences of trans* people by refuting a reductionist diagnosis - which has indeed always been unwelcome in psychoanalysis - and placing subjectivity centre stage.

\section{REFERENCES}

American Psychiatric Association (APA). (1952). Diagnostic and Statistical Manual of Mental Disorders. Washington, DC: Author.

American Psychiatric Association (APA). (1968). Diagnostic and Statistical Manual of Mental Disorders, 2nd Edition. Washington, DC: Author.

American Psychiatric Association (APA). (1980). Diagnostic and Statistical Manual of Mental Disorders, 3rd Edition. Washington, DC: Author.

American Psychiatric Association (APA). (1987). Diagnostic and Statistical Manual of Mental Disorders, 3rd Edition revised. Washington, DC: Author.

American Psychiatric Association (APA). (1994). Diagnostic and Statistical Manual of Mental Disorders, 4th Edition. Washington, DC: Author. 
American Psychiatric Association (APA). (2000). Diagnostic and Statistical Manual of Mental Disorders, 4th Edition text revised. Washington, DC: Author.

American Psychiatric Association (APA). (2013). Diagnostic and Statistical Manual of Mental Disorders, 5th Edition. Arlington, VA: American Psychiatric Publishing.

Amodeo, A. L., Picariello, S., Valerio, P., \& Scandurra, C. (2018). Empowering transgender youths: Promoting resilience through a group training program. Journal of Gay and Lesbian Mental Health, 22(1), 3-19. doi: 10.1080/19359705.2017.1361880

Argentieri S. (2009). Transvestism, transsexualism, transgender: Identification and imitation. In: Ambrosio G., editor, Transvestism, Transsexualism in the Psychoanalytic Dimension. London: Karnac.

Bartlett, N. H., Vasey, P.L., \& Bukowski, W. M. (2000). Is gender identity disorder in children a mental disorder? Sex Roles, 43, 753-785.

Beek, T. F., Cohen-Kettenis, P. T., \& Kreukels, B. P. (2016). Gender incongruence/gender dysphoria and its classification history. International Review of Psychiatry, 28(1), 5-12. DOI:10.3109/09540261.2015.1091293

Benjamin J. (1995). Like Subjects, Love Objects. New York: Yale University Press (trad. it.: Soggetti d'amore. Milano: Raffaello Cortina, 1996).

Bradley, S. J., \& Zucker, K. J. (1997). Gender identity disorder: a review of the past 10 years. Journal American Academy of Child and Adolescent Psychiatry, 36(7), 872-880. doi: 10.1097/00004583-199707000-00008.

Bradley, S. J., Blanchard, R., Coates, S., Green, R., Levine, S. B., Meyer-Bahlburg, H. F. L., \& Zucker, K. J. (1991). Interim report of the DSM-IV Subcommittee on Gender Identity Disorders. Archives of Sexual Behavior, 20(4), 333-343. doi: 10.1007/BF01542614

Butler J. (1990). Gender Trouble: Feminism and the Subversion of Identity. New York: Routledge.

Cauldwell, D. O. (1949). Psychopathia Trans-sexualis, Sexology Magazine.

Chiland C. (1997). Changer de sexe. Paris: Editions Odile Jacob.

Cohen-Kettenis, P. T. (2001). Gender identity disorder in DSM? J Am Acad Child Adolesc Psychiatry, 40, 391.

Cohen-Kettenis, P. T., \& Pfäfflin, F. (2010). The DSM Diagnostic Criteria for Gender Identity Disorder in Adolescents and Adults. Archives of Sexual Behavior, 39(2), 499-513. doi:10.1007/s10508-009-9562-y

De Cuypere, G., \& Knudson, G. (2015). Gender incongruence of childhood: yes or no-a survey among WPATH members. First Biennial Conference of the European Professional Association for Transgender Health; Ghent, Belgium; March 12-14, 2015.

Deogracias, J. J., Johnson, L. L., Bradley, S. J., Kibblewhite, S. J., Owen-Anderson, A., \& Zucker, K. J. (2010). The gender identity/gender dysphoria questionnaire for adolescents and adults: Further validity evidence. Journal of Sex Research, 47(1), 49-58. doi:10.1080/00224490902898728

Dimen M. (1991). Deconstructing Differences: Gender, Splitting and Transitional Space. Psychoanalytic Dialogues, 1: 335-352 (Trad. it.: La decostruzione del genere. Milano: il Saggiatore, 2006). doi: 10.1080/ 10481889109538904

Drescher, J. (2010). Queer diagnoses: Parallels and contrasts in the history of homosexuality, gender variance, and the Diagnostic and Statistical Manual (DSM). Archives of Sexual Behavior, 39, 427-460.

Drescher, J., \& Byne, W. (2013). Treating transgender children and adolescents: An interdisciplinary discussion. New York, NY: Routledge.

Drescher, J., Cohen-Kettenis, P. T., and Reed, G. M. (2016). Gender incongruence of childhood in the ICD-11: Controversies, proposal, and rationale. The Lancet Psychiatry. doi:10.1016/S2215-0366(15)00586-6

Drescher, J., Cohen-Kettenis, P., \& Winter, S. (2012). Minding the body: situating gender identity diagnoses in the ICD-11. International Review of Psychiatry, 24, 568-577. 
Ehrbar, R. D., Witty, M. C., Ehrbar, H. G., \& Bockting, W. O. (2008). Clinician judgment in the diagnosis of gender identity disorder in children. Journal of Sex and Marital Therapy, 34(5), 385-412. doi:10.1080/00926230802219398

Fisher, A. D., Bandini, E., Casale, H., Ferruccio, N., Meriggiola, M. C., Gualerzi, A., \& Stomaci, N. (2013). Sociodemographic and clinical features of gender identity disorder: an Italian multicentric evaluation. The Journal of Sexual Medicine, 10(2), 408-419. doi:10.1111/j.1743-6109.2012.03006.x

Giovanardi, G., Fiorini Bincoletto, A., \& Fortunato, A. (2019). Un più vasto orizzonte: psicoanalisi e identità di genere, storia di un rapporto controverso, da Freud ai contemporanei. Psicobiettivo, 3, 133-152.

Giovanardi, G., Morales, P., Mirabella, M., Fortunato, A., Chianura, L., Speranza, A. M., \& Lingiardi, V. (2019). Transition memories: experiences of trans adult women with hormone therapy and their beliefs on the usage of hormone blockers to suppress puberty. Journal of Endocrinological Investigation, 42, 1231-1240. doi:10.1007/s40618-01901045-2

Giovanardi, G., Vitelli, R., Maggiora Vergano, C., Fortunato, A., Chianura, L., Lingiardi, V., \& Speranza, A. M. (2018). Attachment patterns and complex trauma in a sample of adults diagnosed with gender dysphoria. Frontiers in psychology, 9, 60. doi:10.3389 /fpsyg.2018.00060

Gozlan, O. (2018). From Continuity to Contiguity: A Response to the Fraught Temporality of Gender. The Psychoanalytic Review, 105(1), 1-29. doi:10.1521/prev.2018.105.1.1

Haldeman, D. C. (2000). Gender atypical youth: Clinical and social issues. School Psychology Review, 29, 192-200.

Hamburger, C., Stürup, G. K., \& Dahl-Iversen, E. (1953). Transvestism: Hormonal, psychiatric, and surgical treatment. Journal of the American Medical Association, 12(6), 391396.

Harris, A. (1991). Gender as contradiction. Psychoanalytic Dialogues, 1(2), 197-224. doi:10.1080/10481889109538893

Harris, A. (2008). Gender as Soft Assembly. New York: Routledge.

Hill, D. B., Rozanski, C., Carfagnini, J., \& Willoughby, B. (2006). Gender identity disorders in childhood and adolescence: A critical inquiry. Journal of Psychology and Human Sexuality, 17, 7- 34.

Hirschfeld, M. (1910), Die Transvestiten, eine Untersuchung uber den erotischen Verkleidungstrieb mit umfangreichem casuistischem und historischem Material, in Medizinischer Verlag, Berlin, Ferdinand Spohr, Leipzig 1925.

Hirschfeld, M. (1923). Die intersexuelle konstitution. Jahrbuch fur Sexuelle Zwischenstufen, 23, 3-27.

Hoyer, N. (1933). Man into Woman: An Authentic Record of a Change of Sex. The True Story of the Miracolous Transformation of the Danish Painter, Einar Wegener. New York: E.P. Dutton and Co.

Isay, R. A. (1997). Remove gender identity disorder in DSM. Psychiatric News, 32, 9-13. Lingiardi, V., \& McWilliams, N. (Eds.). (2017). Psychodynamic diagnostic manual, 2nd ed. (PDM-2). New York, NY: Guilford Press.

Levine, S. B. (1989). Gender identity disorders of childhood, adolescence, and adulthood. In: H. I. Kaplan \& B.J. Sadock (a cura di). Comprehensive Textbook of Psychiatry. Vol. 1, 5th ed. (pp. 1061-1069). Baltimore: Williams and Wilkins.

Lingiardi, V., Giovanardi, G., Fortunato, A., Nassisi, V., \& Speranza, A. M. (2017). Personality and attachment in transsexual adults. Archives of Sexual Behavior, 46(5), 1313-1323. doi:10.1007/s10508-017-0946-0

Limentani, A. (1979). The significance of transsexualism in relation to some basic psychoanalytic concepts. International Review of Psychoanalysis, 6, 139-153.

McGann, P. J. (2007). Healing (disorderly) desire: Medical-therapeutic regulation of sexuality. 
In S. Seidman, N. Fischer e C. Meeks (eds.), Handbook of the new sexuality studies (pp. 390- 402). London: Routledge.

Meyer-Bahlburg, H. F. (2009). Variants of gender differentiation in somatic disorders of sex development: recommendations for version 7 of the World Professional Association for Transgender Health's Standards of Care. International Journal of Transgenderism, 11(4), 226- 237. doi:10.1080/15532730903439476

Money, J. (1955). Hermaphroditism, gender and precocity in hyperadrenocorticism: Psychologic findings. Bulletin of Johns Hopkins Hospital 96, 253-264.

Money, J. (1994). The concept of gender identity disorder in childhood and adolescence after 39 years. Journal of Sex and Marital Therapy, 20, 163-177.

Narrow, W. E., \& Cohen-Kettenis, P. (2010). The revision of gender identitiy disorder: DSM5 principles and progress. Journal of Gay and Lesbian Mental Health, 14(2), 123-129. doi:10.1080/19359701003600954

Oppenheimer, A. (1991). The Wish for a Sex Change: A Challenge to Psychoanalysis? International Journal of Psychoanalysis, 72(2), 221-231 (trad. it. in P. Valerio et al., eds., Il transessualismo. Saggi psicoanalitici. Milano: FrancoAngeli, 2001).

Paap, M., Kreukels, B. P., Cohen-Kettenis, P. T., Richter-Appelt, H., de Cuypere, G., \& Haraldsen, I. R. (2011). Assessing the utility of diagnostic criteria: A multisite study on gender identity disorder. Journal of Sexual Medicine, 8, 180-190.

PDM Task Force. (Ed.). (2006). Psychodynamic diagnostic manual. Silver Spring, MD: Alliance of Psychoanalytic Organizations.

Ristori, J., Cocchetti, C., Castellini, G., Pierdominici, M., Cipriani, A., Testi, D., \& Cassioli, E. (2020). Hormonal Treatment Effect on Sexual Distress in Transgender Persons: 2-Year Follow-Up Data. The Journal of Sexual Medicine, 17(1), 142-151. doi:10.1016/j.jsxm.2019.10.008

Saketopoulou, A. (2014). Mourning the body as bedrock: Developmental considerations in treating transsexual patients analytically. Journal of the American Psychoanalytic Association, 62(5), 773-806 (trad. it.: Psicoterapia e scienze umane, 1, 7-36, 2015). doi: $10.1177 / 0003065114553102$.

Scandurra, C., Bochicchio, V., Amodeo, A. L., Esposito, C., Valerio, P., Maldonato, N. Bacchini, D., \& Vitelli, Roberto (2018). Internalized transphobia, resilience, and mental health: Applying the Psychological Mediation Framework to Italian transgender individuals. International Journal of Environmental Research and Public Health, 15(3), 508e. doi:10.3390/ijerph15030508

Sedgwick, E. (1993). How to bring your kids up gay. In Sedgwick, E. (ed.), Tendencies (pp. 154-166). Durham, NC: Duke University Press.

Socarides, C.W. (1970). A psychoanalytic study of the desire for sexual transformation ("transsexualism"): The plaster-of-paris man. International Journal of Psychoanalysis, 51, 341349 .

Sood, N. (2009). Transgender people's access to sexual health and rights: a study of law and policy in 12 Asian countries. Kuala Lumpur: Asian-Pacific Resource and Research Centre for Women, 2009.

Spitzer, R. L., \& Wakefield, J. C. (1999). DSM-IV diagnostic criterion for clinical significance: Does it help solve the false positives problem? American Journal of Psychiatry, 156(12), 1856-1864. doi:10.1176/ajp.156.12.1856

Stoller, R. J. (1968). Sex and Gender. London: Karnac Books.

Vitelli, R., Scandurra, C., Pacifico, R., Selvino, M. S., Picariello, S., Amodeo, A. L., \& Giami, A. (2017). Trans identities and medical practice in italy: Self-positioning towards gender affirmation surgery. Sexologies, 26(4), e43-e51. doi:10.1016/j.sexol.2017.08.001

Vance, S. R., Cohen-Kettenis, P. T., Drescher, J., Meyer-Bahlburg, H. F. L., Pfäfflin, F., \& Zucker, K. (2010). Opinions about the DSM gender identity disorder diagnosis: Results from an international survey administered to organizations concerned with the welfare of 
transgender people. International Journal of Transgenderism, 12(1), 1-14. doi:10.1080/15532731003749087

von Krafft-Ebing, R. (1886). Psychopatia Sexualis. Brooklyn: Physicians and Surgeons Book Co.

Winter, S., De Cuypere, G., Green, J., Kane, R., \& Knudson, G. (2016). The Proposed ICD-11 Gender Incongruence of Childhood Diagnosis: A World Professional Association for Transgender Health Membership Survey. Archives of Sexual Behavior, 45(7), 1605-1614. doi:10.1007/s10508-016-0811-6

World Health Organization (WHO). (1975). Report of the international conference for the ninth revision of the international classification of diseases. Geneva: World Health Organization.

World Health Organization (WHO). (1992). The ICD-10 classification of mental and behavioural disorders: Clinical descriptions and diagnostic guidelines. Geneva: World Health Organization.

World Health Organization (WHO). (2015). International Classification of Diseases. Geneva: World Health Organization.

World Health Organization (WHO). (2018). International classification of diseases for mortality and morbidity statistics (11th Revision). Available from: https://icd.who.int/ browse11/1-m/en

World Professional Association for Transgender Health (WPATH). (2013). WPATH consensus process regarding transgender and transsexual-related diagnoses in ICD-11. Available from: http://www.wpath.org/uploaded_files/140/files/ICD\%20Meeting\%20PacketReport-Final- sm.pdf

Zucker, K. J. (2010). The DSM diagnostic criteria for gender identity disorder in children. Archives of Sexual Behavior, 39, 477-498. DOI: 10.1007/s10508-013-0139-4

Zucker, K. J., \& Spitzer, R. L. (2005). Was the Gender Identity Disorder of Childhood diagnosis introduced into DSM-III as a backdoor maneuver to replace homosexuality? A historical note. Journal of Sex and Marital Therapy, 31, 31-42.

Zucker, K. J., Cohen-Kettenis, P. T., Drescher, J., Meyer-Bahlburg, H. F. L., Pfäfflin, F., and Womack, W. M. (2013). Memo outlining evidence for change for gender identity disorder in the DSM-5. Archives of Sexual Behavior, 42(5), 901-914. http://DOI.org/ 10.1007/s10508-013-0139-4.

Conflict of interest: the authors declare no potential conflict of interests.

Ethics approval and consent to participate: the manuscript does not contain any elements that would allow the recognition of the patient.

Received for publication: 4 March 2020.

Accepted for publication: 31 March 2020.

${ }^{\circ}$ Copyright: the Author(s), 2020

Licensee PAGEPress, Italy

Ricerca Psicoanalitica 2020; XXXI:259

doi:10.4081/rp.2020.259

This article is distributed under the terms of the Creative Commons Attribution

Noncommercial License (by-nc 4.0) which permits any noncommercial use, distribution,

and reproduction in any medium, provided the original author(s) and source are credited. 